This is the penultimate draft of a chapter that appears in The

Bloomsbury Handbook of Posthumanism, eds. Mads Rosendhal

Thomsen and Jacob Wamberg (New York: Bloomsbury Academic,

2020), 161-170. Please cite the published version.

\title{
Race, Technology, and Posthumanism
}

\author{
Holly Flint Jones and Nicholaos Jones
}

\begin{abstract}
This chapter briefly reviews the role of race (as a concept) in the history of theorizing the posthuman, engages with existing discussions of race as technology, and explores the significance of understanding race as technology for the field of posthumanism. Our aim is to engage existing literature that posits racialized individuals as posthumans and to consider how studying race might inform theories of the posthuman.
\end{abstract}

Keywords: Anthropocene, cyborg, Enlightenment, eugenics, fiction, racialization

Examining the role of race in the field of posthumanism is a bit like examining race in the genre of science fiction. Science fiction tends to reconstitute what we imagine as race into other forms of exclusion and oppression. When reading or watching science fiction, one often finds cyborgs, genetically altered people, and aliens of various sorts treated as subhumans and second-class citizens, feared for their unfamiliar and incompatible customs, laws, and worldviews. It might be said, accordingly, that science fiction anticipates a future beyond race, at least as we experience race today. But it might also be that science fiction gives us another important insight into the role of race in relation to (post)humanism: race, in the form of exclusion and oppression justified by perceptions of fixed bodily and cultural difference, continues to play a fundamental role in the societies imagined within science fiction because race is and has been one of the most influential technologies to emerge worldwide since the 1500s. As with other paradigm-shifting technologies, race has, in a very material sense, altered our ability to imagine and understand what it means to be-and not to be-(post)human. While such imaginings are not of race, per se, the technologies of race both contextualize and inform them. Likewise, when examining the field of posthumanism, race as such is not often discussed, yet concerns regarding the 
technologies of race-their function and effects-are often front and center when scholars imagine what humans are, are not, and might become.

Our strategy, then, is to identify the role of race-as technology-in the field of posthumanism, even when it might seem that posthumanism (like science fiction) anticipates a future beyond race. Some scholars of posthumanism have suggested that new forms of bodily and environmental Otherness will supersede, and perhaps even erase, the influence and relevance of race for societies as we move forward into the Anthropocene. This may be. But even so, it seems likely that race as technology will continue to shape the societies of the future. As such, those who have been subjected to the most debilitating and exploitative technologies of race have the most to teach us about what one must learn to do-and imagine-in order to survive in an increasingly precarious world created, quite literally, by (if not for) humanity.

\section{EUGENICS, CYBORGS, AND THE POSTHUMAN}

The figure of the posthuman first appears as part of an objection to eugenics as a feasible means of preventing or alleviating poverty. For the eugenicist, science and technology are a means to transform human beings into something that is "more completely human" (Titmuss and Lafitte 1942,106). Science and technology are a means, in particular, for either preventing the birth of those who are intrinsically incapable of social success or else altering intrinsic traits-relating, for example, to efficiency and thrift-in ways that enhance suitability for productive labor.

There are strong (and persuasive) moral objections to the eugenic approach to poverty. But there are technoscientific and economic objections as well. The posthuman makes its appearance in this latter variety of objection. ${ }^{1}$

[I]t is inconceivable that human nature could be changed to the extent that is contemplated by [the eugenicist's] theory of perfectibility. Such changes would bring into being an animal no longer human, or for that matter mammalian, in its character, for it would involve the elimination of such fundamental human and mammalian instincts and emotions as anger, jealousy, fear, etc. But even if such a post-human animal did come into existence, it is difficult to believe that it could carry on the necessary economic activities without using a certain amount of formal organization, compulsion, etc (Parmelee 1916, 319).

\footnotetext{
${ }^{1}$ We thank Andres Pilsch for identifying this appearance.
} 
The posthuman, so conceived, is the human shorn of human instinct and emotion. Since, according to the objection, these characteristics are necessary for motivating effortful work in the absence of external coercion, the posthuman, so conceived, escapes poverty only at the expense of individual liberty. ${ }^{2}$

The eugenic conception of the posthuman stands opposed to the Enlightenment ideal of the human. The complete human, on the Enlightenment ideal, is a sovereign self. He-and, historically, the ideal human is male-exercises sovereignty through individual liberty of choice; he realizes this liberty by subordinating instinct and emotion to reason and rationality; and he uses this liberty to achieve material and social progress, subjecting the chaos of nature, the constraints of biology, and the bonds of tradition to scientific evidence, technological innovation, and rational critique. Insofar as a posthuman society achieves progress only at the expense of individual liberty, the eugenicist, with his preference for the posthuman over the human, stands for domination and subjugation.

Contrast this original conception of the posthuman with more recent conceptions of the posthuman as cyborg (see Hayles 1999; Thweatt-Bates 2012; Braidotti 2013). The cyborg, in these conceptions, is

a cybernetic organism, a hybrid of machine and organism, a creature of social reality as well as a creature of fiction (Haraway 1985, 65).

As social reality, the cyborg is a political construction, a product of social relations that liberate some and oppress others. As creature of fiction, the construction is contingent and therefore malleable, its nature illusory, its dispositions and capacities limited only by imagination (and, perhaps, the power to transform the imagined into reality). The cyborg is, in some sense, the enlightenment ideal of the complete human made real, "an ultimate self untied at last from all dependency" (Haraway 1985, 67). So, too, is the posthuman conceived as cyborg. For insofar as cybernetization makes the human more completely human, the posthuman is likewise untied from all dependency, a sovereign self perfected through fiction-making and social construction.

Eugenic and cyborg conceptions of the posthuman agree that the posthuman is a "more complete" successor to the human. Both agree, as well, that some sort of technology-be it biological/genetic or bionic/engineered-is the

2 Miah attributes to Fukuyama (2002) a similar conception of the posthuman, according to which biotechnological modifications capable of transforming humans into posthumans threaten to corrupt some essential factor of humanity (Miah 2008, 78). 
source of whatever enhancement transforms humans into posthumans. The conceptions disagree, however, about whether technology affords such enhancement by excising or integrating with human characteristics. They thereby also disagree about whether human and mammalian nature is an obstacle or a foundation for human enhancement, and about whether posthuman-inducing enhancements position social progress and individual liberty as oppositional or complementary.

\section{RACE AS TECHNOLOGY}

Set aside the contrasts among eugenic and cyborg conceptions of the posthuman. Focus, instead, on a motivation common to both conceptions, namely, a concern with the place of racialized persons in society. Eugenicists of the early 20th century, especially in the United States and Germany, endorsed-and often saw enacted-policies and programs to control or decimate specific racial populations, for the sake of alleviating social ills such as poverty and criminality. Late 20th and early 21 st century cyborg theorists of the posthuman, by contrast, typically advocate for the liberation of those same populations, for the sake of alleviating race-based injustice and oppression. Despite their different aims and attitudes, however, eugenicists and cyborg theorists connect-if only implicitly—the posthuman to issues of race.

For the past decade, a growing number of scholars of race, working in fields such as Philosophy, Gender Studies, Media Studies, Literary Theory, and Sociology, have been developing a framework that deepens the connection between race and posthumanism. Sheth (2009), Chen (2009), and Coleman (2009) - among other works - argue for the benefits of theorizing race as a technology. This approach to race posits that certain social practices and institutions function as technologies of race; that these technologies create and sustain hierarchies of racial classification; and that individuals are racialized by virtue of how technologies of race rank them within such hierarchies (see Jones and Jones 2017). Insofar as posthumans arise through the technological transformation of humans, and given that technologies of race are ubiquitous in modern societies, theorizing race as technology promises that understanding how race works should illuminate what it is to be posthuman.

Sheth (2009) offers, to date, the most extensive and systematic approach to theorizing race as technology. Sheth argues that those who wield sovereign power create and put into use technologies of race. She argues, further, that these technologies have three basic functions: first, to "channel an element 
that is perceived as threatening to the political order into a set of [racial] classifications;" second, to "transfo[m the] 'unruly' into a set of 'naturalized' criteria upon which race is grounded;" and third, to "concea[l] our relationship to law and sovereign power as one of vulnerability and violence, such that racialized populations stand precariously close to being cast outside the gates of the city" (Sheth 2009, 8).

We can better understand how race works as a technology—and, in particular, how technologies of race assign the social ills of a society to a particular population and then essentialize members of that population as constituting a race-by imagining a small town in Alabama. Imagine that the town's population generally opposes the use of local tax revenues (in the form of vouchers) for private schools. While some families like the idea--there's a small private Catholic school they'd like to send their kids to if the tuition was substantially lower-the majority oppose it.

Imagine, now, that several new families move to town when the local sock company opens a third shift. These families have relocated from Florida. And while these families are not all related to one another, most of them are Catholic. These new families would like to send their children to the local private Catholic school but can't afford it. However, if they combine their support of a proposed voucher system to the minority of families already in favor of it, a new political landscape emerges. Suddenly there's a majority-slim, perhaps--that favors the creation of a new school voucher system that would enable these Catholic families to send their kids to the local private school.

This is where the technologies of race can start to do their work. If those in charge of the local school board can get the people of the town to view the school voucher system as un-Alabamian--a social practice that threatens the identity of the town--they could sway public opinion back to the way it was. It might benefit these leaders of the school board if, along the way, those who posed the threat to the status quo (those families that moved in) were treated as perpetual outsiders so that the locals would continue to shun whatever political agenda these families might support or even propose. If successful, those leaders of the town who wield sovereign power will encourage the local population to see these Floridian families as possessing certain traits--being irrational, dangerous, threatening - incapable of becoming Alabamians-and these come to be associated with their "racial" identity. They are Floridians and always will be.

Once a racialized population comes to be seen as possessing undesirable and threatening traits-and these traits are determined be to the cause of other 
social ills-those who wield the technologies of race can, if unchallenged, maintain their power indefinitely. Like many other modern technologies, the technologies of race are fluid, always changing, responding to whatever political threat the status quo (i.e., those with sovereign power who serve as the technicians of race) might face. As new threats to the political status quo emerge, race as technology adapts, not only preventing whatever targeted population has been radicalized from ever joining the body politic, but also condemning these populations to the status of perpetual precarity, possessing traits that condemn them to the status of outsider and Other.

In short, race is a technology designed to enable those who wield sovereign power to maintain it. And the effects of racialization on raced populations is quite simply devastating. But what's so maddening for those of us seeking points of intervention into the politics of racialization is that race (as a technology) is so good, so smart, so adaptive, that it conceals not only it techniques but also the cognitive contradictions that result as it works over time. Race might essentialize a quality or trait to a certain population at one point and then it can essentialize an oppositional quality within the same population at a later date and the technology conceals itself in such a way that people who use it are conditioned not to notice. The technologies of race employed in the 1860s can essentialize slaves in the American South as crafty, sneaky, always plotting their escape, dangerous to all white people who may at any time face armed rebellion and/or attack. And then 50 years later these same technologies can essentialize the opposite: now black Southerners are racialized to be categorically ignorant, incapable of self -reflection and awareness, and so must be prevented (via Jim Crowe laws) from participating in community governance.

The whole premise of race--and the essentialism it creates-is that these traits are supposed to be fixed, unchanging. And yet 50 years can pass and black Southerners are still black but their essential traits have changed while at the same time the very notion of blackness - of having a fixed, biological essence-remains. Race as a technology is so very good at maintaining the status quo that we, as the members of a society that heavily utilizes the technology, are trained to not notice, to not see the techniques by which it functions.

\section{ARE RACIALIZED INDIVIDUALS POSTHUMAN?}

Technologies of race create and sustain hierarchies of racial classification, and they racialize individuals by attaching to them a rank within some socially salient racial hierarchy. Those who wield sovereign power are thereby transformed into members of a superior race. Those who threaten sovereign 
power, or who are perceived or positioned as threatening that power, by contrast, are transformed into members of a subordinate race. Insofar as posthumans are humans transformed by technology, theorizing race as technology seems to entail that racialized individuals are posthuman by default, always already transformed beyond the (merely) human by virtue of living in a racialized society.

But matters are not quite so straightforward. Whether the entailment holds depends upon whether racialized individuals qualify as antecedently human. Insofar as posthumans are "more complete" humans, whether the entailment holds also depends upon whether those who qualify as human are capable of becoming more complete. If racialized individuals are not antecedently human, they cannot have their humanity transformed and so cannot be posthuman. But even if they are antecedently human, if their humanity cannot be transformed into the more completely human, they cannot be posthuman either.

Societies influenced by modern European culture, whether through ancestry or colonization, offer conceptual resources that support conflicting answers to the question of whether racialized individuals are posthuman. Consider, first, that such societies tend to be familiar with the European Enlightenment's ideal of the human, according to which humans are complete insofar as, and to the extent that, their choices and behaviors exercise or enact sovereign powerpower free from the tethers of history and the restrictions that attend dependence upon others. This ideal, together with the posit that race is a technology, seem to entail, on the one hand, that those racialized as superior are posthuman because technologies of race enhance their sovereignty. But the enlightenment ideal, and the posit of race as technology, also seem to entail, on the other hand, that those racialized as subordinate are not posthuman because they lack sovereignty and thereby cannot become more completely human. (It is, accordingly, perhaps unsurprising that periods in which the Enlightenment ideal of the human holds sway are periods in which those racialized as subordinate are considered to be less than human.)

In contrast to the Enlightenment-oriented approach to the posthuman, consider, second, the approach prominent in the popular culture of societies influenced by modern European culture. This approach tends to depict some-but certainly not all-posthumans as subordinately racialized individuals. ${ }^{3}$ Popular examples of cyborgs depicted as subordinately racialized include Cyborg (Vic Stone) from DC Comics, Darth Maul in the Clone

3 We note an irony here. If those racialized as subordinate are always already posthuman, the eugenic motivation for creating posthumans-namely, fear of unruly races-is itself sufficient for creating posthumans. 
Wars era of the Star Wars sage, Baxter Stockman from Teenage Mutant Ninja Turtles, and the protagonists in Octavia Butler's Xenogenesis (1989). González (1995) notes, as further evidence of this tendency, that the language used in popular culture to describe cyborgs often resembles the language used to describe mixed-race persons. Nishime (2005) argues, as well, that modern cinema, by displacing issues about race onto narratives about cyborgs, tends to suppose that being racialized as subordinate is constitute of being a cyborg.

Enlightenment-oriented and popular culture-inspired approaches to the posthuman agree that nothing prevents those who are racialized as superior from qualifying as posthuman. They disagree, however, about whether an apparent lack of sovereignty disqualifies those who are racialized as subordinate from being posthuman. There are, accordingly, and in the context of theorizing race as technology, three options for resolving the issue of whether those racialized as subordinate are posthuman. The first is to endorse the Enlightenment ideal of the complete human and yet deny that being racialized as subordinate forestalls exercises of sovereignty. The second is to endorse the Enlightenment ideal of the complete human and concede that subordinately racialized individuals are not posthuman. The third, finally, is to reject the Enlightenment ideal and work to construct an alternative whereby being racialized as subordinate is no obstacle to being (or becoming) more completely human.

The first of these options has its origins in Haraway's (1985) early work on cyborgs. The strategy here is to acknowledge that the Enlightenment ideal of the human is racist while simultaneously maintaining that all racialized individuals attain that ideal. This involves theorizing that fiction-making and social construction work in ways that give sovereignty to those racialized as subordinate. Endorsing the Enlightenment ideal of the complete human, while denying that racialization as subordinate forestalls exercises of sovereignty, offers an ironic approach to the posthuman. The approach endorses a racist ideal of the complete human, condemns its racist fallout, and optimistically maintains that reconceptualizing subordinately racialized individuals as cyborgs somehow liberates them from that fallout. But, as Aguilar Garciá (2008) notes, this approach "does not specify in what way or why the communion with the inorganic is a sort of upheaval for the oppressed" (translated and quoted in Sued 2018, 97). Moreover, the imagining of ethnocyborgs whose technological prostheses rebel against their bodies and threaten violence to others demonstrates that being a (subordinately racialized) mestiza/o cyborg does not, in and of itself, entail being a human who is made more complete through integration with a technology, especially when the technology at issue is race (see Pitman 2016, 224). 
Critical race theory lends support to the second option for resolving the issue of whether those racialized as subordinate are posthuman. Prior to the rise of posthuman theorizing, structural asymmetries in power relations between those racialized as superior and those racialized as subordinate fostered social and political divisions between those treated as "human" and those treated as "other," with "human" typically reserved for those who are white, and "other" typically reserved for those who are not (see Wynter 2003, 281-282). Posthumanist theory, similarly, at least on the Enlightenment-oriented approach, reproduces this same division-albeit reconceptualized as a division between those who are "posthuman" (white) and not (see Ali 2017). Whence Forlano notes,

From the perspective of critical race studies, it is not productive to speak of the posthuman when so many people-non-white, less privileged/powerful, female, older, indigenous, people with disabilities, and so on-have not been historically included in the category of the human in the first place (Forlano 2017, 28).

Since the historical record shows that those racialized as subordinate also tend to be classified and treated as less than human, the argument goes, and since the posthuman is inextricably tied to this history, there is no conceptual space or practical use for positing subordinately racialized posthumans. Better, perhaps, to focus, instead, on the shifting boundaries between human and nonhuman-and for those concerned with issues of race to ally themselves with theorists in animal studies rather than with posthumanists (see Livingston and Puar 2011; Jackson 2013).

Those who pursue the third option for resolving the issue of whether those racialized as subordinate are posthuman tend to abstain from positing a univocal ideal of the human. They tend to prefer, instead, instead a more fragmental approach whereby the many ways of being human-and so of being more completely human-need not point toward a notion of humanity that is common to all. Braidotti, for example, maintains that

the posthuman - a figuration carried by a specific cartographic reading of present discursive conditions - can be put to the collective task of constructing new subjects of knowledge, through immanent assemblages or transversal alliances between multiple actors (2019, 36)

In place of a unitary ideal that unites differently racialized humans as humans, Braidotti prefers assemblages and alliances that construct new meanings of what it is to be (completely) human. Siddiqui (2016), similarly, proposes 
expanding conceptions of the human in ways that include those who have historically been excluded while also equalizing the legitimacy of different conceptions.

\section{SURVIVING POSTHUMANISM}

Despite her earlier preference for an ironic posthumanism, Haraway now prefers to focus on animal studies and rejects the posthuman approach. According to Haraway's more recent thinking, the notion of posthumanism

is much too easily appropriated by the blissed-out, 'Let's all be posthumanists and find our next teleological evolutionary stage in some kind of transhumanist technoenhancement'. Posthumanism is too easily appropriated to those kinds of projects for my taste (as quoted in Gade 2006, 140).

Haraway concedes, however, that more critical approaches to the posthuman are possible, citing Hayles (1999) as an example. There are, moreover, some efforts to put a critical conceptual of the posthuman to work in ways that help to further theorizing about race and racialization. By theorizing that people racialized as subordinate qualify as posthuman, these efforts point toward fruitful associations between what we know about the lives of subordinately racialized populations and what we might expect for the lives of those living as posthumans more broadly.

Consider, for example, an especially salient characteristic of contemporary life, namely, its extreme precarity. Ours is the era of the Anthropocene, when human impacts upon the natural environment mean that the conditions necessary for life as we have known it are no longer givens. Posthumanists tend to treat anthropogenic impacts as one (among several) fundamental motivations to theorize ourselves as posthuman (see Eroukhmanoff and Harker 2017; Propen 2018). Whence Braidotti conceptualizes posthuman theory as

a generative tool to help us re-think the basic unit of reference for the human in the bio-genetic age known as 'anthropocene', the historical moment when the Human has become a geological force capable of affecting all life on this planet $(2013,5)$.

Ferrando (2016), similarly, ascribes responsibility for the negative impacts on the environment to an anthropocentric worldview, arguing that addressing 
these impacts requires decentering the "human" and, instead, centering the "posthuman."

Absent from many posthumanist approaches to the Anthropocene, however, is attention to issues of race-such as how anthropogenic changes to the environment differentially impact racialized populations, and what differently racialized populations of posthumans might contribute to responding to those changes. This is, perhaps, part of a larger tendency to neglect the racial dimensions of environmental change (see Vergès 2017, Tuana 2019). But the absence is surprising nonetheless. For, as Gergan, Smith, and Vasudevan (forthcoming) argue, fictionalized narratives about apocalyptic futures for the Anthropocene tend to act as proxies for fears of racialized "others" and the decline of racial supremacies.

Posthumanists concerned with the Anthropocene ought not neglect issues of race. Subordinately racialized populations-American chattel slaves, Jewish persons from the Holocaust, Muslims targeted as extremists, Latina/o migrants at the United States border, to name some obvious examples-have much to teach about surviving times of despair, when conditions for sustainable living are out of reach and forces abound that threaten to overwhelm efforts to change course. Mary Annaïse Heglar, for example, connects the Anthropocene and race through the lens of existential threat. She argues that, far from being a unique threat to human existence, the changing climate of the Anthropocene is akin to the changing environment for Black people through the history of the United States.

I'll grant that we've never seen an existential threat to all of humankind before. It's true that the planet itself has never become hostile to our collective existence. But history is littered with targeted-but no less deadly-existential threats for specific populations.

For 400 years and counting, the United States itself has been an existential threat for Black people. Let's be clear that slavery didn't end with freedom; it just morphed into a marginally more sophisticated, still deadly machine (Heglar 2019).

We should expect, therefore, that the strategies Black people in the United States have been using to survive in a hostile environment will prove to be relevant for devising strategies survive anthropogenic climate change. ${ }^{5}$ If the

${ }^{4}$ Ahuja 2017 notes, as well, that posthumanists are comparatively more concerned with the extinction of nonhuman species than theorists of animal studies.

${ }^{5}$ Insofar as surviving climate change involves adapting strategies from those who have been racialized as subordinate, it is, perhaps, unsurprising to find that people more invested in 
posthuman is a vehicle for imagining how to survive the Anthropocene, posthumanists would do well to imagine the paradigmatic posthuman as a subordinately racialized individual. They would do well, also, to turn their attention from fictionalized utopias and imagined alternative history, toward political realities of the present and the histories of subordinately racialized populations.

\section{SOURCES CITED}

Aguilar Garciá, T. (2008), Ontología cyborg: el cuerpo en la nueva sociedad tecnológica. Barcelona: Gedisa.

Ahuja, N. (2017), "Posthuman New York: Ground Zero of the Anthropocene." In M. Lundblad (ed.), Animalities: Literary and Cultural Studies Beyond the Human. Edinburgh: Edinburgh University Press. 43-59.

Ali, S.M. (2017), "Transhumanism and/as Whiteness." Proceedings 1, 244.

Benegal, S.D. (2018), "The Spillover of Race and Racial Attitudes into Public Opinion about Climate Change." Environmental Politics 27 (4): 733-756.

Braidotti, R. (2013), The Posthuman. Malden, MA: Polity Press.

Braidotti, R. (2019), "A Theoretical Framework for the Critical Posthumanities." Theory, Culture \& Society 36.2: 31-62.

Butler, O. (1989), Xenogenesis. New York: Guild America Books.

Chun, W. (2009), "Introduction: Race and/as Technology; or, How to Do Things with Race." Camera Obscura 24.1: 7-35.

Coleman, B. (2009), "Race as Technology." Camera Obscura 24 (1): 176-207.

Eroukhmanoff, C. and M. Harker (eds.). (2017), Reflections on the Posthuman in International Relations: The Anthropocene, Security and Ecology. Bristol: E-International Relations Publishing.

maintaining a racially supremacist status quo tend also to resist acknowledging or addressing the impacts of climate change (see Benegal 2018). 
Ferrando, F. (2016), "The Party of the Anthropocene: Post-humanism, Environmentalism and the Post-Anthropocentric Paradigm Shift." Relations 4 (2): 159-173.

Forlano, L. (2017), "Posthumanism and Design." She Ji: The Journal of Design, Economics, and Innovation 3 (1): 16-29.

Fukuyama, F. (2002), Our Posthuman Future: Consequences of the Biotechnology Revolution. London: Profile Books.

Gade, N. (2006), " When We Have Never Been Human, What Is to Be Done?: Interview with Donna Haraway." Theory, Culture \& Society 23 (7-8): 135-158.

Gergan, M., S. Smith, and P. Vasudevan. (forthcoming), "Earth Beyond Repair: Race and Apocalypse in Collective Imagination." Environment and Planning D: Society and Space.

González, J. (1995), "Envisioning Cyborg Bodies: Note from Current Research." In C.H Gray, S. Mentor, and H.J. Figueroa-Sarriera (eds.), The Cyborg Handbook. New York: Routledge. 267-279.

Haraway, D. (1985), "A Manifesto for Cyborgs: Science, Technology and Socialist Feminism in the 1980s." Socialist Review 80: 65-108.

Hayles, N.K. (1999), How We Became Posthuman: Virtual Bodies in Cybernetics, Literature, and Informatics. Chicago: University of Chicago Press.

Heglar, M.A. (2018), "Climate Change Ain't the First Existential Threat." Medium, February 18. Online at https://medium.com/s/story/sorryyall-but-climate-change-ain-t-the-first-existential-threatb3c999267aa0

Jackson, Z.I. (2013), "Animal: New Directions in the Theorization of Race and Posthumanism." Feminist Studies 39 (3): 669-685.

Jones, H. and N. Jones. (2017), "Race as Technology: From Posthuman Cyborg to Human Industry." Ilha do Desterro 70 (2): 39-51.

Livingston, J. and J.K. Puar. (2011), "Interspecies." Social Text 29 (1): 3-14. 
Miah, A. (2008), "A Critical History of Posthumanism." In B. Gordijn and R. Chadwick, Medical Enhancement and Posthumanity. New York: Springer. 71-94.

Nishime, L. (2005), "The Mulatto Cyborg: Imagining a Multiracial Future." Cinema Journal 44 (2): 34-49.

Parmelee, M. (1916), Poverty and Social Progress. New York: Macmillan.

Pitman, T. (2016), "Mestizaje and Cyborgism on Either Side of the Line." In J.M. González (ed.), Cambridge Companion to Latina/o Literature. New York: Cambridge University Press. 213-230.

Propen, A.D. (2018), Visualizing Posthuman Conservation in the Age of the Anthropocene. Columbus: The Ohio State University Press.

Siddiqui, J.R. (2016), "Human Equality Projects as Prerequisites for a Posthuman Embrace." Educação Temática Digital 18 (2): 458-464.

Titmuss, R.M. and F. Lafitte. (1942), "Eugenics and Poverty." The Eugenics Review 33 (4): 106-112.

Thweatt-Bates, J. (2012), Cyborg Selves: A Theological Antropology of the Posthuman. Burlington, VT: Ashgate.

Tuana, N. (2019), "Climate Apartheid: The Forgetting of Race in the Anthropocene." Critical Philosophy of Race 7 (1): 1-31.

Sheth, F. (2009), Toward a Political Philosophy of Race. Albany: State University of New York Press.

Sued, G.E. (2018), "The Cyborg metaphor in Ibero-American Science, Technology and Gender Literature." Tapuya: Latin American Science, Technology and Society 1 (1): 95-108.

Vergès, F. “Racial Capitalocene.” In G.T. Johnson and A. Lubin (eds.), Futures of Black Radicalism. New York: Verso. 72-82.

Wynter, S. (2003), "Unsettling the Coloniality of Being/Power/Truth/Freedom: Towards the Human, After Man, Its Overrepresentation-An Argument." CR: The New Centennial Review 3 (3): 257-337. 


\section{AUTHOR BIOGRAPHIES}

Holly Flint Jones is an Emeritus Associate Professor of English at The University of Alabama in Huntsville. Nicholaos Jones is a Professor of Philosophy at The University of Alabama in Huntsville. Their joint research focuses on understanding racialization as an industrial technology. 